
\title{
CIÊNCIANATURA
}

\section{Avaliação da chuva prevista em curto prazo por radar meteorológico}

\author{
Evaluation of weather radar rainfall estimation for nowcasting
}

Luiz Carlos Salgueiro Donato BacelarI; Carlos Frederico de Angelis ${ }^{I I}$

IInstituto Nacional de Pesquisas Espaciais, Brasil

II Instituto Nacional de Pesquisas Espaciais, Brasil

\section{Resumo}

Este artigo traz a primeira avaliação do método utilizado pelo Centro Nacional de Monitoramento e Alerta de Desastres Naturais para os prognósticos em curto prazo da precipitação por radares meteorológicos. Nesta avaliação foram estudados quatro casos de chuva intensa no raio de cobertura do radar Pico do Couto, que originaram alertas de risco para o município de nova Friburgo, no estado do Rio de Janeiro. Em relação aos dados pluviométricos in situ, foi observada uma subestimativa mediana de $43 \%$ da precipitação pelo radar ao utilizar o método SRI (Surface Rainfall Intensity). Após a correção dos campos de chuva, a metodologia para extrapolação por cross-correlation (correlação cruzada) foi avaliada para os horizontes de previsão de 30, 60, 90 e 120 minutos, com a precipitação acumulada a cada 30 minutos. As probabilidades de detecção (POD) obtiveram maiores valores para limiares de chuva mais baixos (pelo menos 1 ou $5 \mathrm{~mm}$ de chuva acumulada) ao comparado com acumulados de chuva maiores (20 e $30 \mathrm{~mm}$ ), como observado em estudos anteriores. Da mesma forma, as séries espaciais e temporais de chuva apresentaram maiores erros (MAE e RMSE) para os prognósticos de 90 e 120 minutos de previsão. Em todos os eventos foi observada uma superestimativa (PBIAS positivo) média das previsões em relação ao próprio campo observado de chuva do radar.

Palavras-chave: Nowcasting, hidrometeorologia, estimativa de chuva, precipitação, sensoriamento remoto

\section{Abstract}

This article presents the first evaluation of the method used by the Brazilian Centre for Monitoring and Early Warning of Natural Disasters for the short term forecast (nowcasting) of precipitation by weather radar. In this evaluation, four cases of intense rainfall in the radius of Pico do Couto radar were studied, giving the flood risk alerts sent for the municipality of Nova Friburgo, in the state of Rio de Janeiro. In relation to rain gauge data, a median under rate of $43 \%$ for the radar precipitation was observed when using the SRI (Surface Rainfall Intensity) method. After the rainfall correction, the cross-correlation extrapolation method was evaluated for the 30,60, 90 and 120 minute forecast horizons, with accumulated precipitation every 30 minutes. The probabilities of detection (POD) obtained higher values for lower rainfall thresholds (at least 1 or 5 mm of accumulated rainfall) when compared to larger amount accumulated $(20$ and $30 \mathrm{~mm})$. The spatial and temporal series of rainfall presented higher errors (MAE and RMSE) for 90 and 120 minutes of forecast. For all the events, an overestimate (PBIAS positive) of the predictions was observed in relation to the observed radar rain field itself.

Keywords: nowcasting, hydrometeorology, rainfall estimation, precipitation, remote sensing 


\section{1 introdução}

O termo "nowcasting" se refere ao intervalo temporal de previsões meteorológicas em um curto prazo, que pode variar entre zero a seis horas. Eventos meteorológicos extremos que ocorrem neste intermédio, como chuvas fortes, granizos ou vendavais são usualmente monitorados através de sensores remotos da atmosfera. As técnicas existentes para melhor diagnostico e prognostico das nuvens via radares ou satélites, desempenham um papel fundamental para minimizar os danos socioeconômicos associados às ameaças naturais (Tominaga et al., 2009; UCAR, 2010; Ceped-UFSC, 2012). Contudo, as limitações que ainda persistem ao descrever processos meteorológicos nesta escala temporal, aumentam as incertezas das estimativas de chuva, sejam no tempo presente ou em futuro bem próximo.

Muitas das técnicas desenvolvidas para prognósticos das tempestades por sensoriamento remoto incorporam métodos de tracking, que equivalem ao acompanhamento da atividade convectiva das células de precipitação ao longo do seu ciclo de vida. As áreas de maior atividade convectiva são determinadas por imagens de radar meteorológico ou satélite, em modo diagnostico no tempo presente. Através de metodologias como TREC (Rastogi et al., 1978), TITAN (Dixon e Wiener, 1993) ou FORTACC (Vila et al., 2009), os históricos da identificação e rastreamento das tempestades ajudam a estimar o seu próprio deslocamento. Nestes casos, a tendência do movimento das nuvens é empregada em prognostico para prever sua localidade no futuro. Como descrito pelos autores, parte das incertezas para previsão das tempestades aparecem na suposição de sua direção e tempo de deslocamento, que influenciam por consequência as estimativas futuras de precipitação.

A aplicabilidade dos métodos de estimativa de chuva é importante não só na perspectiva meteorológica, mas também contribui em áreas afins que necessitam de campos espacializados de precipitação. Para hidrólogos ou geocientistas, os dados de chuva estimados por radar auxiliam ao acesso a informações em áreas suscetíveis a desastres hidro meteorológicos em que a rede pluviométrica ainda é escassa (Intrieri et al., 2012; Thorndahl e Rasmussen, 2013; Thorndahl et al., 2013). Tendo em vista a capacidade de prever os cenários meteorológicos que deflagram esses desastres, os prognósticos auxiliam na obtenção dos acumulados de chuva antes da ocorrência das inundações ou deslizamentos. Alguns sistemas operacionais no mundo já incorporam o nowcasting da chuva por sensores remotos para monitoramento de ameaças naturais que transcendem a meteorologia. Países como os Estados Unidos mantém politicas publicas especificas para inundações bruscas que se beneficiam das previsões em curto prazo em seus alertas antecipados (UCAR, 2010). Nielsen et al. (2014) e Thorndahl e Rasmussen (2013) demonstraram a aplicabilidade das técnicas em modelos hidrológicos para previsão de cheias na Dinamarca. Isso faz com que os efeitos das previsões de curto prazo ainda sejam objeto de estudo e aprimoramento por parte de diversos pesquisadores.

No Brasil, a utilização de dados de chuva estimada por sensores remotos é crescente à medida que a demanda por sistemas de prevenção a desastres naturais aumentam no país. Nos últimos anos, devido a inúmeras perdas por desastres naturais envolvendo elementos sociais e econômicos (Ceped-UFSC, 2012), o governo brasileiro investiu na ampliação da rede de monitoramento pluviométrico em todo território nacional. Com a aquisição de 10 novos radares meteorológicos, os dados de estimativa de chuva e prognósticos tendem a ser cada vez mais empregados para monitoramento das condições meteorológicas que deflagrem desastres naturais. Anteriormente, algumas metodologias para prever a chuva por sensoriamento foram aplicadas em ambiente operacional, destacando aqui o hidrotrac (Vicente et al., 1998) em imagens infravermelho do satélite GOES-12, e as campanhas de experimentos meteorológicos, que inclui radares atmosféricos, do projeto SOS CHUVA (Machado et al., 2017). Apesar das técnicas terem sido implementadas em tempo real, pouco existe na literatura sobre a avaliação dos impactos das previsões no território nacional. É oportuno neste momento investigar as incertezas principalmente das metodologias correntes e de maior utilização, evidenciado pela singularidade dos sistemas meteorológicos brasileiros.

Este artigo traz a primeira avaliação do método unificado de prognósticos da chuva, em utilização operacional para todos os radares meteorológicos existentes no banco de dados do Centro Nacional de Monitoramento e Alerta de desastres Naturais (Cemaden). O objetivo principal do estudo é comparar o resultado das previsões em curto prazo dos radares com os campos observados de chuva do próprio radar. Os eventos de chuva intensa selecionados para analise ocorreram no raio de cobertura do Radar Pico do Couto, em busca de favorecer uma analise robusta sobre todo o estado do Rio de Janeiro. As incertezas das previsões da precipitação serão demonstradas através de índices estatísticos que comparam as series temporais dos prognósticos com os diagnósticos. A tabela de contingencia empregada para analise espacial calcula os índices de acerto dos prognósticos em prever determinadas quantidades de chuva, o que ajuda a demonstrar o grau de confiabilidade das previsões. Desta forma, espera-se apontar quais etapas necessitam maior atenção ao considerar a técnica de previsão por radares meteorológicos.

\section{Dados e Metodologia}

\subsection{Eventos extremos}

Os quatro eventos selecionados para este estudo caracterizam alguns casos de chuva intensa, que segundo o Cemaden, originaram alertas de risco de inundação brusca para o município de Nova Friburgo, no estado do Rio de Janeiro. Avaliar o desempenho dos prognósticos da chuva por radar meteorológico é importante para aferir o grau de confiabilidade na manutenção dos alertas de risco, que na maioria das circunstancias de desastres hidrometeorologicos, necessitam de uma quantificação estimada da chuva. 
Tabela 1: Especificações técnicas do Radar Pico do Couto

\begin{tabular}{cc}
\hline Especificações do Radar & Banda S \\
\hline Frequência & 2.7 a $2.9 \mathrm{GHz}$ \\
Comprimento de Onda & $10.9 \mathrm{~cm}$ \\
Potencia & $850 \mathrm{~kW}$ \\
Alcance Máximo & $400 \mathrm{~km}$ \\
Alcance Quantitativo & $250 \mathrm{~km}$ \\
Resolução do Alcance & $500 \mathrm{~m}$ \\
Resolução Angular & 1 grau \\
Largura de feixe & 2 graus \\
Resolução do dado & Z, uZ, V e W \\
Rotação & 18 graus/segundo \\
& $0.5,1.0,1.9,2.9,3.9,4.9,5.9$, \\
Elevação das Varreduras & $6.9,7.9,8.9,9.9,12,14,16 \mathrm{e} 18$ \\
& graus \\
\hline
\end{tabular}

Dependendo dos cenários de risco instalados, poucos milímetros de chuva acumulada pode diferenciar um nível de alerta, entre moderado, alto e muito alto. Por isso, para os casos de 29/11/2013, 12/04/2014, 27/09/2014 e 02/01/2015 a chuva começou a ser contabilizada antes do inicio das precipitações mais intensas até o final do evento chuvoso, que em todos os quadros configuram quatro dias correntes de observações (192 passos de tempo, acumulados a cada 30 minutos). De acordo com as analises sinóticas reportadas pelo Centro de Previsão de Tempo e Estudos Climáticos do Instituto Nacional de Pesquisas Espaciais, todos os boletins meteorológicos das datas estudadas descrevem a origem da precipitação por processos convectivos associados a uma convergência de umidade na região do estado do Rio de Janeiro. Nenhum dos casos apresentados aqui está correlacionado com passagens de sistemas frontais sobre o a região de influencia do radar.

\subsection{Radar meteorológicos e rede de pluviômetros}

O Radar meteorológico Pico do Couto foi instalado no município de Petrópolis, Estado do Rio de Janeiro, na década de 90 e continua atualmente em operação pelo Departamento de Controle Aéreo Brasileiro (DECEA), em sua recente configuração provendo campos de refletividade a cada 10 minutos. Apesar do radar doppler WSR-88D ser atualmente considerado um protótipo antigo, em relação aos novos radares de dupla polarização instalados no Brasil, sua localização precisa permite uma cobertura completa do estado do Rio de Janeiro, viabilizando condições eficientes de monitoramento, inclusive para a região serrana fluminense. Situado em $43.2972^{\circ} \mathrm{O}$ e $22.4643^{\circ} \mathrm{S}$, a 1760 metros de altura, as varreduras do radar Pico do Couto permitem pouca interferência do sinal eletromagnético devido ao terreno montanhoso no entorno. Neste estudo serão utilizados todos os dados no raio de influência quantitativa do radar $(250 \mathrm{~km})$, em uma resolução horizontal de aproximadamente $1 \mathrm{~km}$, estruturado, portanto, em matrizes de 500 linhas por 500 colunas. Algumas especificações técnicas sobre o radar Pico do Couto podem ser encontradas na Tabela 1.

Na Figura 2.2 além do raio de cobertura do radar são apresentadas as localizações dos pluviômetros que compõem a rede de monitoramento automático de precipitação no estado do Rio de Janeiro, utilizadas neste estudo. No total são 281 estações pluviométricas que transmitem dados sub-horários, no mínimo a cada 15 minutos, em operação pelo Instituto Estadual do Meio Ambiente do Rio de Janeiro (INEA) e Cemaden. Esta rede pluviométrica automática, que permite uma resolução temporal dos dados compatíveis ao estudo e monitoramento de tempestades, começou a ser consolidada em 2013 com o financiamento do Plano Nacional de Redução do Risco a Desastres Naturais (PNRRDN). As estações estão situadas em áreas estratégicas suscetíveis a desastres hidrometeorológicos, como inundações e movimentos de massa, que são deflagrados após intensas precipitações ou grande valores acumulados. Ambas as informações de precipitação, proveniente de estações pluviométricas e radar meteorológico, foram extraídos do banco de dados do Cemaden, que abriga hoje um dos mais completos bancos de dados de precipitação em alta resolução do país.

Os dados dos pluviômetros foram acumulados a cada 30 minutos a partir do início de cada evento chuvoso. Vale ressaltar que o numero de pluviômetros em funcionamento disponíveis para as análises são diferentes em cada caso estudado. Para minimizar os efeitos de dados faltantes, só foram considerados pluviômetros que apresentaram medições em mais de $90 \%$ do total de passos de tempo. Os eventos são nomeados durante o texto de acordo com a data de início das análises.

\subsection{Estimativa de precipitação e nowcasting}

Atualmente no Cemaden as estimativas de chuva por radares são geradas com a suposição de representarem a camada de chuva mais próxima da superfície (Surface Rainfall Intensity - SRI). Essa metodologia elabora os campos de chuva considerando a 
Figura 1: Raio de varredura do radar Pico do Couto (400km - laranja ), estações pluviométricas automáticas (pontos azuis) sobre o estado do Rio de Janeiro com modelo digital de elevação (DEM) SRTM - resolução espacial de 250m.

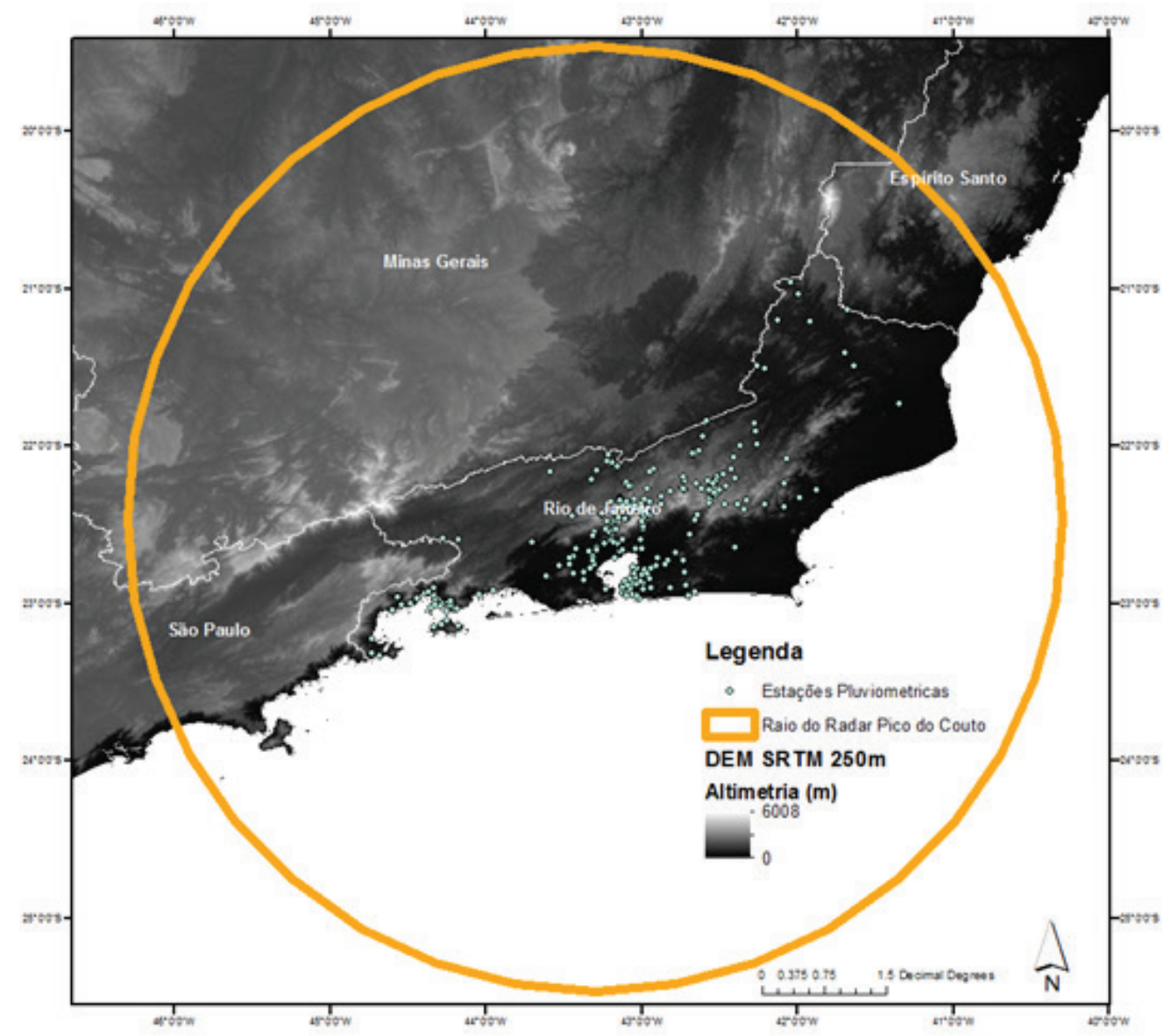

topografia do terreno no raio de alcance do radar meteorológico. Ao contrario de algumas estimativas de chuva que atribuem as refletividades em um angulo de elevação (PPI) ou altura constante (CAPPI) o SRI agrega a informação de diferentes ângulos de elevação, em alturas variáveis. O modelo digital de elevação do Shuttle Radar Topographic Mission (SRTM) com 250 metros de resolução horizontal descreve a orografia que permite classificar as áreas onde dado do radar pode ser considerado invalido devido à interferência do pulso eletromagnético no terreno. De acordo com o algoritmo, a estimativa da chuva é realizada a partir de duas alturas fixas, neste caso do radar do Pico do Couto entre 500 metros e $5 \mathrm{~km}$ acima do radar. Os dados de refletividade são interpolados entre os campos com diferentes ângulos de elevação (PPI) que formam o nível do SRI (Figura 2.3). Após o estabelecimento do campo de refletividade no nível SRI são aplicadas duas relações Z-R (Equação 1) para estimar a precipitação no domínio radial do radar. O ajuste dessas relações refletividade-chuva parte da classificação de chuvas convectivas e estratiformes por Steiner et al. (1995); Biggerstaff e Listemaa (2000). O algoritmo se baseia no dado volumétrico da refletividade aplicado à diferentes índices da relação Z-R, dependo da altura da varredura. Até o momento, nenhum tipo de correção é realizado após a estimativa da precipitação no nível SRI pela relação Z-R. Para compatibilidade com os dados de precipitação das estações pluviométricas, as estimativas de chuva por radar também seguem o acumulo em milímetros a cada 30 minutos.

$$
Z=a \cdot R^{b}
$$

Onde, $Z$ é a refletividade $(D b z), R$ a taxa de chuva $(\mathrm{mm} / \mathrm{h}), a$ e $b$ coeficientes de ajuste.

O método de prognóstico dos campos de chuva utiliza uma técnica conhecida como "cross correlation" (correlação cruzada) para estimar as áreas futuras de precipitação baseando-se no movimento das células convectivas, entre uma imagem no tempo passado e outra no presente. Os algoritmos de tracking geralmente dividem uma grade cartesiana de reflectividade do radar ou taxa de chuva em uma série e, em seguida, encontram a advecção da grade que maximiza a correlação cruzada (ou alguma outra medida em similaridade) entre etapas de tempo sucessivas nos dados. O vetor de advecção média para cada grade contendo chuva é então calculado aplicando alguma forma de restrição para minimizar a divergência dos vetores resultantes. No método aplicado nesta dissertação, em principio, toda a imagem é correlacionada em uma resolução reduzida a fim de determinar o movimento global dos sistemas precipitantes. As áreas de chuva são delimitadas utilizando a metodologia de Smart Segmentation, que localiza 
Figura 2: Representação do nível SRI (linha em vermelho) a partir dos ângulos de elevação do radar entre duas alturas fixas.

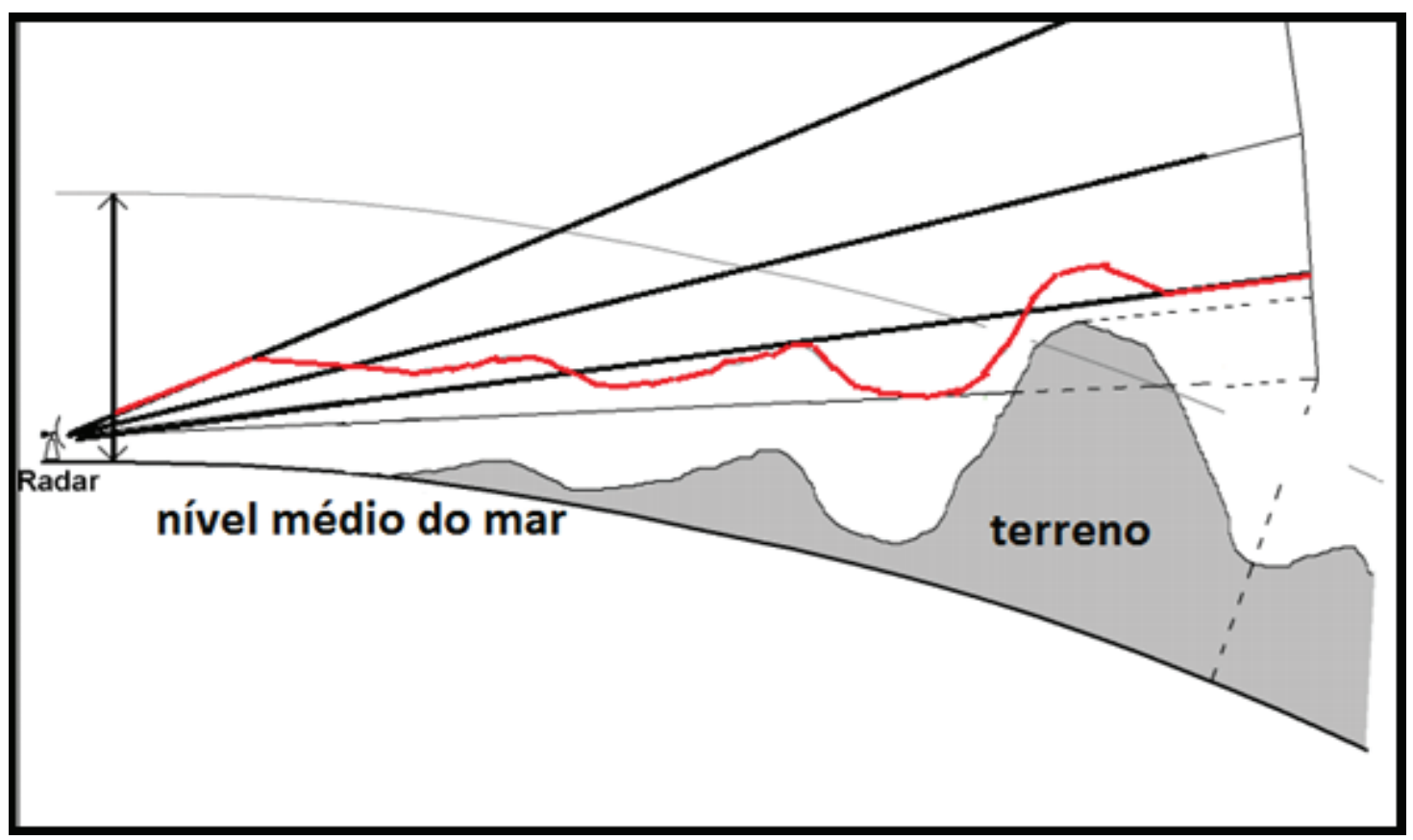

Fonte: Āaptado de SELEX (2012)

os centroides $\vec{C}$ da precipitação baseando-se em limiares dinâmicos de acordo com os valores máximos e mínimos da chuva em cada imagem (Equação 2).

$$
\vec{C}=\frac{\int_{A} w(\vec{r}) \cdot \vec{r} \cdot d a}{\int_{A} w(\vec{r}) \cdot d a}
$$

Onde, $\int_{A}(\ldots)$ exemplifica a integração em duas dimensões em uma célula de área A. A função de proporção $w(\vec{r})$ é correspondente a diferença do valor e o limiar dinâmico pré-estabelecido. Depois de delimitado cada centroide, as áreas de chuva são correlacionadas nas duas imagens, tanto em forward, do tempo passado para o presente, como em backward, do presente para o passado. O movimento das áreas é estimado pelos vetores que identificam a correlação do movimento nas duas imagens. Neste caso, cada área de chuva tem sua direção de movimento prescrito na posição dos centroides nos tempos presente e passado. A posição dos centroides $\varphi_{i}$ e seu movimento $u_{i}$ são utilizados para calcular o posicionamento das áreas de precipitação $\pi_{i}$ com sua incerteza do direcionamento $R_{i j}$ em cada passo de tempo (Equação 3), considerando a variação entre os tempos $\Delta t=t_{0}-t-1$.

$$
R_{i j}=R_{o}+a \cdot u_{i} \cdot \Delta t+b \frac{r_{i}+r_{j}}{2}
$$

Onde $R_{o}$, $a$ e $b$ são constantes modificáveis no algoritmo. No caso do Radar Pico do couto a incerteza inicial $R_{o}$ é tomada como $3 \mathrm{~km}$ com os fatores de ponderação $a=0.3$ e $b=1$. As variáveis $r_{i}$ e $r_{j}$ descrevem o raio equivalente das células de precipitação no tempo passado e presente respectivamente.

Se nos campos de chuva projetados, o raio de influencia de algumas células indicarem o posicionamento futuro para uma mesma região as células podem se unir, ou no caso contrario se dividir. O método é capaz de representar os processos de acoplamento e separação de núcleos de chuva, que por vezes ocorrem na dinâmica da atmosfera. Isso é descrito pela Equação 4 , onde a expressão $\|(\ldots)\|$ indica a distancia horizontal .

$$
\left\|\varphi_{i}-\pi_{i}\right\|>R_{i j}
$$

Com isso, o método de tracking e projeção do campo de chuva por cross-correlation também considera seu potencial de expansão ou diminuição das áreas precipitantes. Os vetores de movimento são, portanto o resultado da busca pela maior correlação entre as áreas de precipitação em as duas imagens de tempos diferentes, como mencionado anteriormente tanto em forward como 
em backward. Mais informações sobre o método de projeção podem ser encontrados no manual do usuário do software Rainbow 5 (SELEX, 2012).

\subsection{Métricas de erros e avaliação do desempenho}

Com o intuído de dimensionar de maneira quantitativa as previsões de curto prazo pelo método de cross-correlation, a tabela de contingencia sugerida por Dixon et al. (1993) foi empregada entre os diagnósticos e prognósticos do radar. A capacidade dos prognósticos em prever com precisão a localidade dos acumulados de chuva será avaliada com base nos índices de acerto para os limiares de chuva de pelo menos 1, 5, 10, 20 e 30 milímetros. No caso do mesmo pixel estar em um valor igual ou superior ao limiar, tanto no diagnóstico como no prognostico, é definido como um acerto de sucesso. Uma falha representa um pixel no prognostico que não está igual ou acima do limiar na imagem do diagnóstico. Em um falso alarme, o pixel previsto pelo radar se mostra igual ou superior ao limiar, porém não se confirma na imagem do diagnóstico. Ao computar o numero (n) de ocorrência de sucessos, falhas e falsos alarmes, são calculados os índices de probabilidade de detecção (POD), falso alarme (FAR) e de sucesso crítico (CSI), a partir das equações:

$$
\begin{gathered}
P O D=\frac{n_{\text {sucesso }}}{n_{\text {sucesso }}+n_{\text {falhas }}} \\
F A R=\frac{n_{\text {falsoalarme }}}{n_{\text {sucesso }}+n_{\text {falsoalarme }}} \\
C S I=\frac{n_{\text {sucesso }}}{n_{\text {sucesso }}+n_{\text {falhas }}+n_{\text {falsoalarme }}}
\end{gathered}
$$

Para avaliar a diferença entre a média de precipitação das estações pluviométricas, o diagnóstico do radar e seus prognósticos para o mesmo ponto, foram escolhidos três índices estatísticos: erro absoluto médio (MAE), raiz do erro quadrático médio (RMSE) e o bias percentual (PBIAS).

$$
\begin{gathered}
M A E=\frac{1}{N} \sum_{i=1}^{N}\left|P_{i}-O_{i}\right| \\
R M S E=\sqrt{\frac{1}{N} \sum_{i=1}^{N}\left(P_{i}-O_{i}\right)^{2}} \\
P B I A S=100 \frac{\sum_{i=1}^{N}\left(P_{i}-O_{i}\right)}{\sum_{i=1}^{N} O_{i}}
\end{gathered}
$$

Em que os valores de chuva média do diagnóstico do radar e dos pluviômetros são tomados como os pontos de observação $O_{i}$ e comparados com os valores de previsão $P_{i}$ dos prognósticos do radar para 30, 60, 90 e 120 minutos. O número $\mathrm{N}$ da amostra são os tempos dos eventos estudados para as médias espaciais ou o número de pluviômetros para as médias temporais. No caso do MAE e RMSE quanto maiores os valores, maior é o erro entre as observações e as previsões. O PBIAS indica o percentual de subestimação, em caso de valores negativos, ou de superestimação quando os valores são positivos, dos prognósticos de chuva do radar. Por uma limitação da formula, os pontos com valores de séries acumulados observados iguais a zero não foram calculados o PBIAS.

\section{Resultados de Discussões}

O intuito da análise inicial foi investigar e expor algumas das limitações associadas aos dados de estimativa de precipitação por radar, em modo diagnóstico e prognóstico, através da comparação com as medições in situ da rede pluviométrica automática. A Figura 3 representa um exemplo dos acumulados espaciais totais de precipitação por radar para toda sua área de cobertura e tempo de análise, neste caso para o evento 02/01/2015. Os acumulados em diagnóstico demonstram a estimativa de chuva observada pelo radar e seus prognósticos pelo método de cross-correlation para 30, 60, 90 e 120 minutos. É possível averiguar que visualmente os campos de prognóstico apresentam semelhança em magnitude e posicionamento dos maiores núcleos de acumulados de precipitação, em comparação com o diagnóstico. A precipitação na "borda" do raio do radar sofre mais interferência da metodologia de previsão por extrapolação.

A Figura 4 demonstra os resultados do acumulado de chuva a cada 30 minutos, em diagnóstico e prognóstico do radar, entre as 18h30min e 20h30min do dia 13/04/2014. É possível visualizar a diferença entre os núcleos de precipitação previstos e ocorridos dos acumulados em um passo de tempo a cada 30 minutos. Nos prognósticos, a intensidade da chuva é mantida a partir 
Figura 3: Acumulado total (mm) para evento com inicio em 02/01/2015: estimativa de chuva em diagnóstico e prognósticos por radar meteorológico
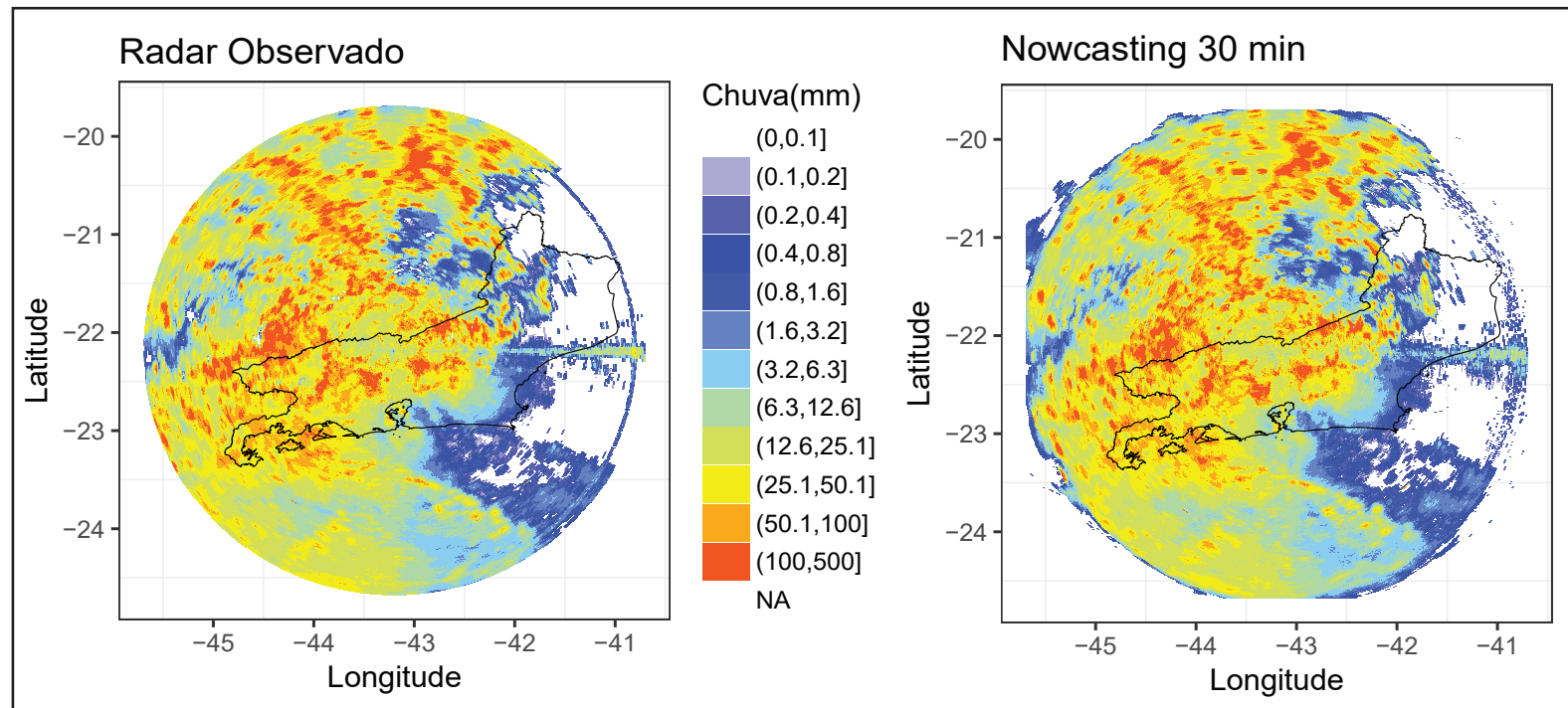

Chuva $(\mathrm{mm})$

$(0,0.1]$

$(0.1,0.2$

$(0.2,0.4]$

$(0.4,0.8]$

$(0.8,1.6]$

$(1.6,3.2]$

$(3.2,6.3]$

$(6.3,12.6]$

$(12.6,25.1]$

$(25.1,50.1]$

$(50.1,100]$

$(100,500]$

NA

Nowcasting 60 min

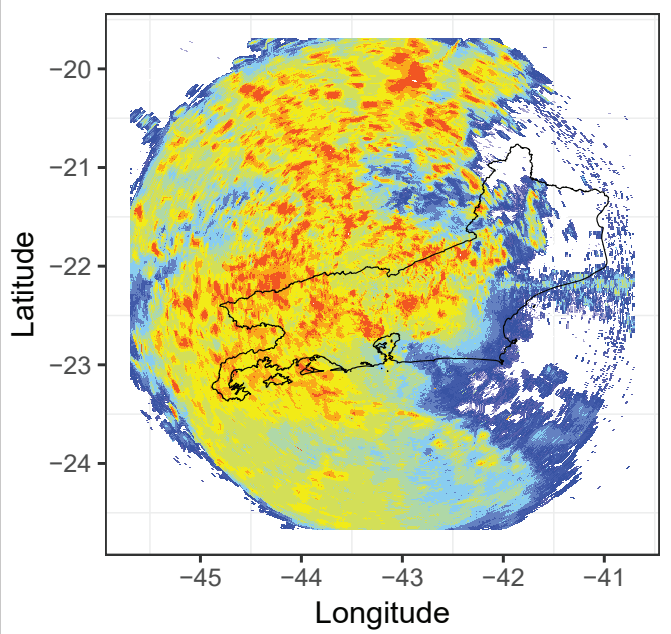

Nowcasting 120 min

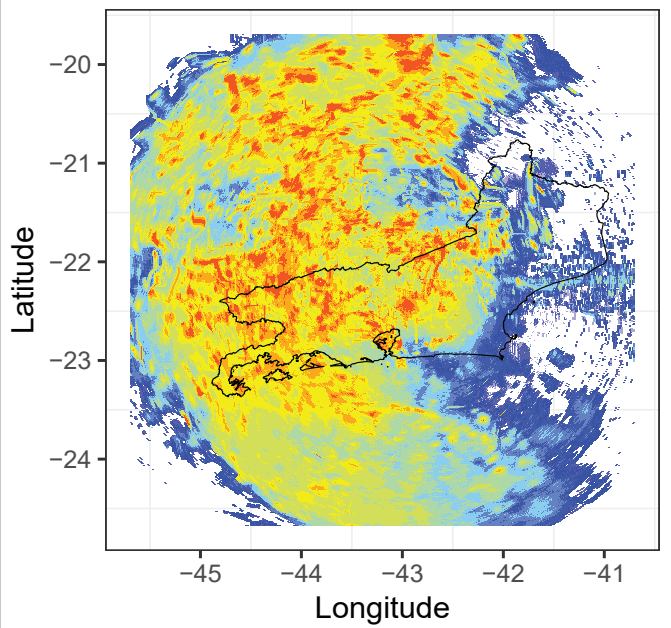

Chuva(mm) $(0,0.1]$

$(0.1,0.2]$

$(0.2,0.4]$

$(0.4,0.8]$

$(0.8,1.6]$

$(1.6,3.2]$

$(3.2,6.3]$

$(6.3,12.6]$

$(12.6,25.1]$

(25.1,50.1]

$(50.1,100]$

$(100,500]$

NA

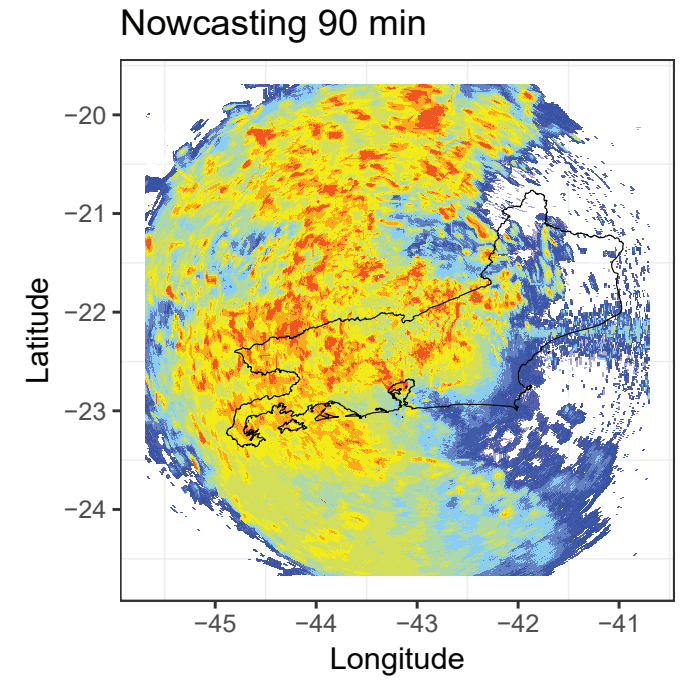

Chuva(mm)

$(0,0.1]$

$(0.1,0.2]$

$(0.2,0.4]$

$(0.4,0.8]$

$(0.8,1.6]$

$(1.6,3.2]$

$(3.2,6.3]$

$(6.3,12.6]$

$(12.6,25.1]$

$(25.1,50.1]$

$(50.1,100]$

$(100,500]$

NA
Chuva(mm)

$(0,0.1]$

$(0.1,0.2]$

$(0.2,0.4]$

$(0.4,0.8]$

$(0.8,1.6]$

$(1.6,3.2]$

$(3.2,6.3]$

$(6.3,12.6]$

$(12.6,25.1]$

$(25.1,50.1]$

$(50.1,100]$

$(100,500]$

NA 
Figura 4: Exemplo do diagnóstico (sequencia à esquerda) da chuva acumulada em 30 minutos a partir do dia 13/04/2014 às 18h30min e seu prognóstico (sequencia à direita) para 30, 60, 90 e 120 minutos.
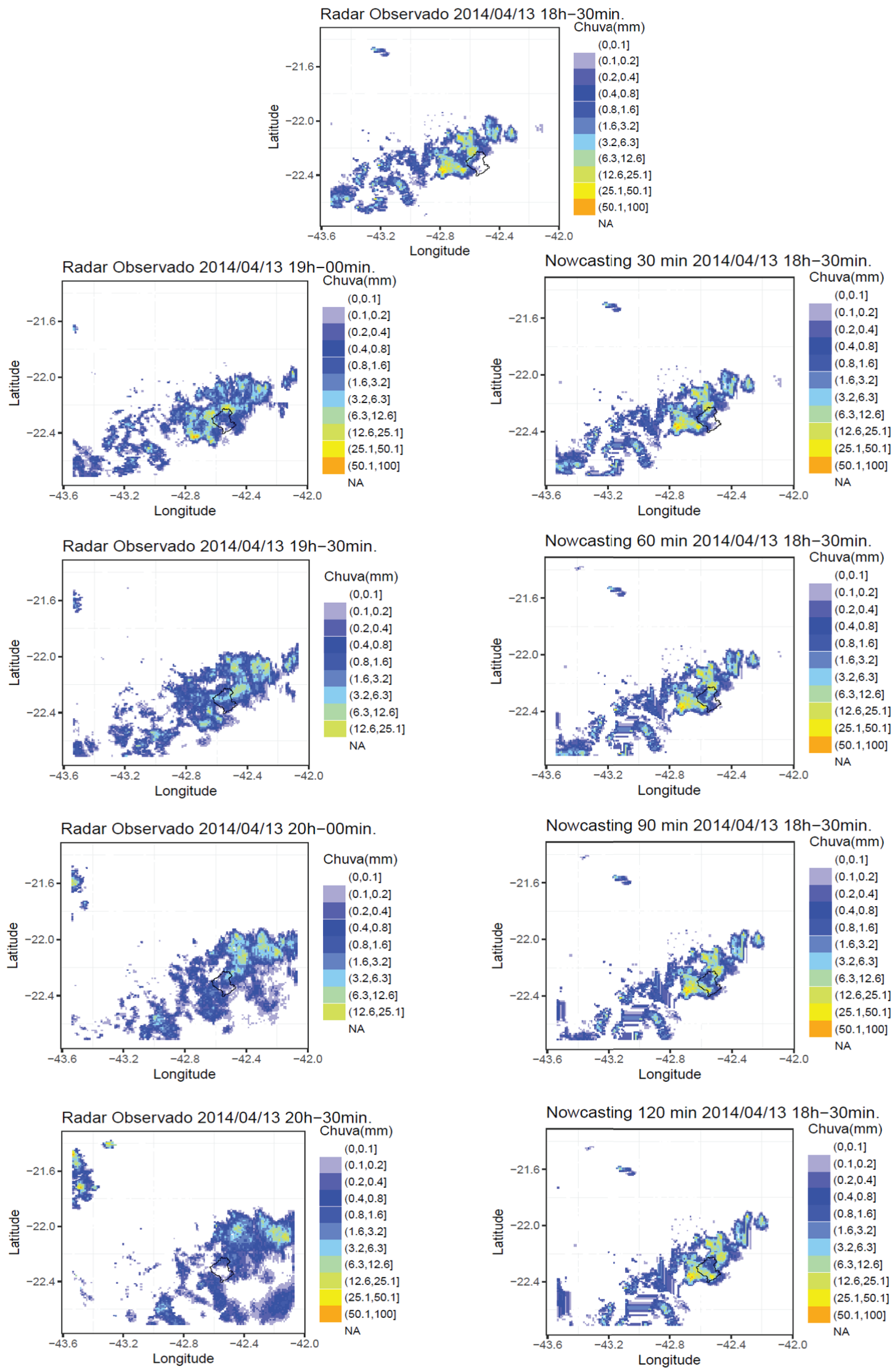
do horário que ocorrem as previsões, no caso 18h30min, como se o campo de chuva fosse deslocado ou extrapolado para os próximos horizontes temporais. No início deste exemplo, a chuva apresenta agrupamentos intensos de atividade convectiva, com isso, a previsão para 120 minutos após se mantém com um conglomerado de núcleos fortes precipitação. Porém as imagens de diagnóstico demonstram que houve uma redução dos acumulados de precipitação a partir das 19h00min para esta área do radar, com a precipitação se deslocando para nordeste.

Se comparados os posicionamentos dos núcleos de chuvas do último horário, às 20:30 horas em diagnóstico, e sua previsão 120 minutos atrás, é detectada uma das limitações da metodologia em inserir um mecanismo para intensificação e desintensificação das células convectivas. Este tipo de análise também é observado em outros métodos que utilizam o cross-correlation para prognósticos de dados via sensores remotos. Germann e Zawadzki (2004) e Seed (2003) avaliaram pelo método de tracking TITAN a correlação entre os horizontes temporais de previsão e a escala espacial dos núcleos convectivos. As influencias dos prognósticos com 2 horas de antecedência permanecem até $50 \mathrm{~km}$, ou seja, para prever mais precisamente o deslocamento dos núcleos de chuva com 2 horas de antecedência sua área deve representar em média um domínio de $50 \mathrm{~km}$ nas imagens. Neste caso, a dependência escala-temporal aumenta progressivamente, visto que para um horizonte de 30 minutos sua correlação é de 8 $\mathrm{km}$. Quanto maior as extensões das precipitações, maior pode ser sua capacidade de ser prevista nos próximos horizontes. Isso demonstra a dificuldade de se antecipar diante de pequenas extensões de chuva, porém intensas, que podem por vezes deflagrar desastres hidrometeorológicos.

Para analisar a variabilidade da intensidade da precipitação nos casos estudados, foram calculadas as médias espaciais da chuva nos pluviômetros, assim como no ponto que os presentam nas imagens de radar em diagnóstico e prognóstico. Ou seja, em cada passo de tempo de 30 minutos, foi computada uma média espacial entre todos os pontos de monitoramento, conforme a rede pluviométrica descrita no capítulo anterior. Vale ressaltar que o número da amostra varia em cada evento estudado, pois para descartar a interferência de dados faltantes foram considerados pontos em que os pluviômetros demonstraram funcionamento em no mínimo $90 \%$ do tempo do evento analisado. A partir disso foi observado um erro sistemático da estimativa de chuva por radar. Considerando todos os casos, foi encontrada uma subestimativa mediana de $43 \%$ da chuva observada do radar em relação aos pluviômetros. A fim de corrigir esta subestimativa detectada, foi decidido aplicar um fator de correção de 1.43 em todos os pixels de chuva estimada pela relação Z-R, bem como em seus prognósticos.

Não foi considerada nesta correção a diferença entre as estimativas de chuvas intensas e chuvas menos intensas, chuvas convectivas ou estratiformes. Porém, estas estatísticas são interessantes de serem analisadas, visto que todas as estimativas de chuva do Cemaden estão sendo elaboradas considerando a metodologia de SRI pelo software Rainbow 5 . Esta correção multiplicativa se faz necessária vista a qualidade das estimativas pelo radar Pico do Couto, que não é de dupla polarização como os novos radares sintalados no território brasileiro. Em estudos anteriores, Bacelar et al. (2013) demonstraram que as estimativas de chuva pelo radar Pico do Couto também comprovam uma subestimativa sistemática, na média em 111\% para uma estimativa de chuva derivada do CAPPI de $3 \mathrm{~km}$ e $104 \%$ derivada do PPI da primeira elevação. Nestes eventos analisados o método o qual determina uma altura SRI para estimar a chuva pode apresentar uma melhora significativa nas estimativas de chuva por radar.

Após a aplicação do fator de correção nos dados de radar, as médias espaciais foram recalculadas e demonstradas na Figura 5. Os gráficos em boxplot ajudam a representar como são os conjuntos de médias das precipitações nos diferentes dados de precipitação considerados. A correção emposta ajudou notoriamente os dados de radar a se aproximar das médias dos pluviômetros, visto que os valores de mediana não diferem significantemente em magnitude entre as estimativas. Também é possível visualizar que independente dos eventos de chuva, os prognósticos poderiam demonstrar tanto uma subestimativa como uma superestimava da chuva em relação ao próprio diagnóstico do radar ou dos pluviômetros. Embora não seja o principal enfoque deste artigo, é oportuno expor as incertezas da própria estimativa de chuva por radar, antes de avaliar também a qualidade de seus prognósticos.

Com o propósito de avaliar o erro das médias da precipitação entre os diagnósticos e prognósticos, os índices estatísticos foram aplicados às séries temporais de médias espaciais e temporais de precipitação. As médias espaciais de chuva representam a média da precipitação entre os pontos de pluviômetro em cada passo de tempo. Neste caso, as médias temporais da precipitação são elaboradas a partir da média pluviométrica no tempo total do evento para cada estação pluviométrica. Para poder avaliar os resultados, é comum a escolha dos índices MAE e RMSE para comparar séries de observação e simulação em estudos hidrológicos, assim, tomando os diagnósticos do radar como os campos observados de chuva, e os prognósticos como os campos simulados. De acordo com a Tabela 2 são possíveis constatar que na maioria dos casos, os índices apresentam melhores resultados nas previsões de 30 min de antecipação. Apesar de diminuir progressivamente o desempenho dos índices estatísticos para as previsões de 60, 90 e 120 minutos, todos os valores de MAE e RSME são maiores ao se comparar com os prognósticos de 120 minutos com os diagnósticos de estimativa de chuva.

Ao se comparar os índices de todos prognósticos entre as médias espaciais e temporais, percebe-se que os menores valores são mostrados nas médias temporais dos prognósticos. Isso pode indicar um comportamento em que os prognósticos apresentam maior desempenho em descrever as médias temporais das chuvas do que os valores de precipitação no espaço. O PBIAS, aplicado às medias temporais e espaciais de chuva, reflete o erro percentual entre os prognósticos e diagnósticos do radar. Neste caso, os valores positivos do PBIAS indicam que todos os prognósticos aparentam superestimar os valores de precipitação, tanto em suas médias temporais como espaciais. O comportamento entre as séries são relacionamos, a superestimava parece ser menor à medida que os horizontes de previsão são mais próximos do tempo presente. Porém os prognósticos de 90 minutos parecem superestimar 
Figura 5: Média espacial (acima) e temporal (abaixo) dos dados pluviométricos para os eventos analisados: antes (esquerda) e depois (direita) da correção pelo fator multiplicativo de 1.43 .

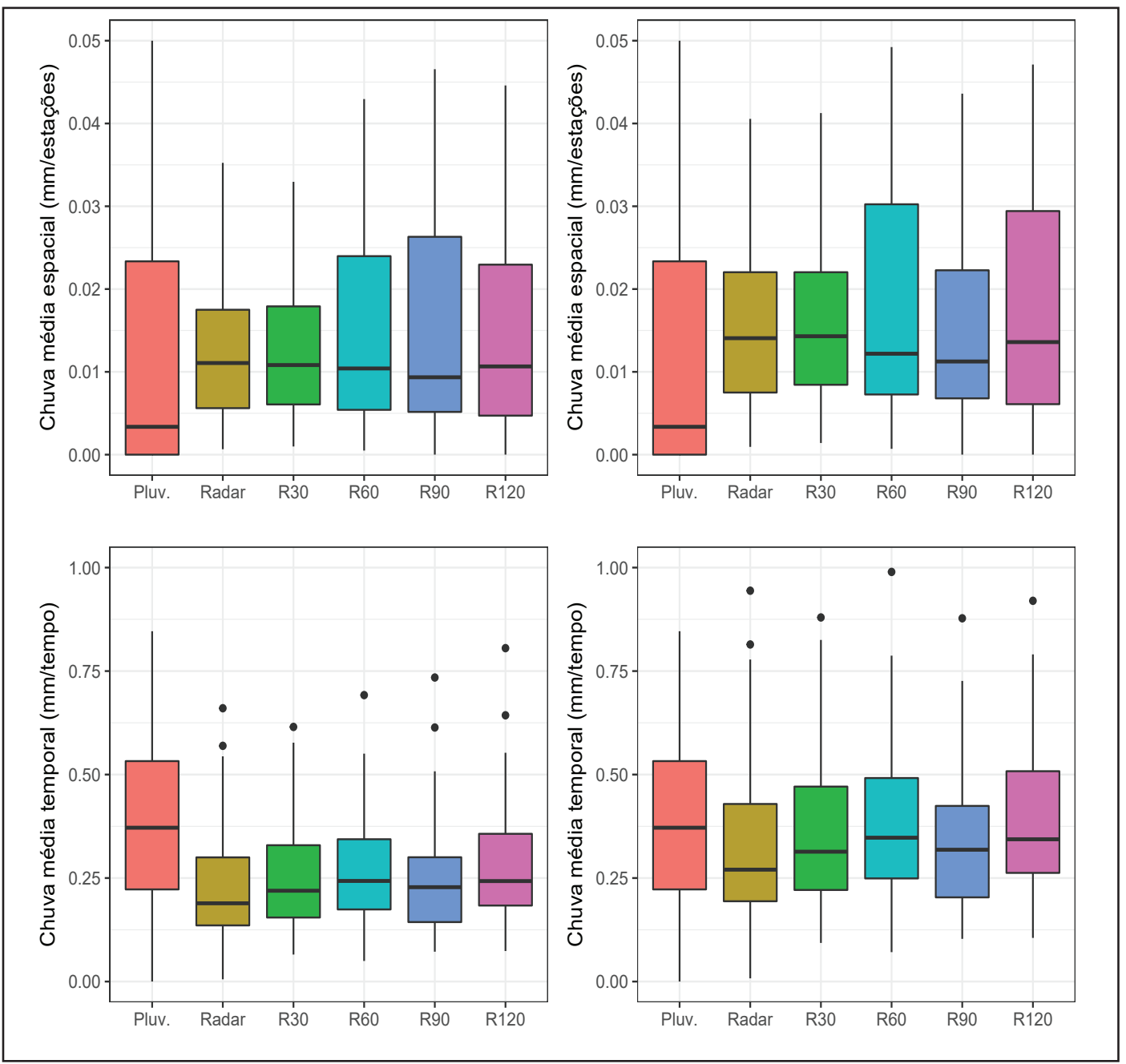

Tabela 2: Resultado dos índices estatísticos para as séries espaciais e temporais entre o diagnóstico e prognósticos da estimativa de chuva por radar.

\begin{tabular}{|c|c|c|c|c|c|c|c|c|c|}
\hline & \multirow[b]{2}{*}{$\begin{array}{c}\text { Previsões } \\
\text { (min) }\end{array}$} & \multicolumn{4}{|c|}{ Média espacial } & \multicolumn{4}{|c|}{ Média temporal } \\
\hline & & 30 & 60 & 90 & 120 & 30 & 60 & 90 & 120 \\
\hline \multirow{5}{*}{ MAE } & $29 / 11 / 2013$ & 0.17 & 0.25 & 0.22 & 0.30 & 0.15 & 0.19 & 0.16 & 0.19 \\
\hline & $12 / 04 / 2014$ & 0.04 & 0.05 & 0.07 & 0.08 & 0.03 & 0.03 & 0.05 & 0.04 \\
\hline & $29 / 11 / 2013$ & 0.05 & 0.06 & 0.07 & 0.08 & 0.05 & 0.05 & 0.06 & 0.06 \\
\hline & $02 / 01 / 2015$ & 0.16 & 0.23 & 0.33 & 0.35 & 0.09 & 0.14 & 0.19 & 0.16 \\
\hline & média & 0.10 & 0.15 & 0.17 & 0.20 & 0.08 & 0.11 & 0.11 & 0.11 \\
\hline \multirow{5}{*}{ RMSE } & $29 / 11 / 2013$ & 0.64 & 0.83 & 0.59 & 0.71 & 0.21 & 0.26 & 0.23 & 0.26 \\
\hline & $12 / 04 / 2014$ & 0.09 & 0.10 & 0.17 & 0.17 & 0.05 & 0.05 & 0.08 & 0.06 \\
\hline & $29 / 11 / 2013$ & 0.16 & 0.17 & 0.24 & 0.26 & 0.08 & 0.09 & 0.10 & 0.09 \\
\hline & $02 / 01 / 2015$ & 0.59 & 0.87 & 1.45 & 1.28 & 0.18 & 0.23 & 0.30 & 0.28 \\
\hline & média & 0.37 & 0.50 & 0.61 & 0.61 & 0.13 & 0.16 & 0.18 & 0.17 \\
\hline \multirow{5}{*}{ PBIAS } & $29 / 11 / 2013$ & 8.4 & 20 & 5 & 21.3 & 9 & 21.2 & 6.7 & 23.9 \\
\hline & $12 / 04 / 2014$ & 5.6 & -2.2 & 8.1 & 3.1 & 6.1 & -1.3 & 9.5 & 5 \\
\hline & $29 / 11 / 2013$ & 12.2 & 29.4 & 53.4 & 43.3 & 11.3 & 28.2 & 51 & 41.3 \\
\hline & $02 / 01 / 2015$ & 16.1 & 39 & 58.8 & 38.8 & 16.7 & 40.4 & 61.2 & 41.6 \\
\hline & média & 10.57 & 21.55 & 31.32 & 26.62 & 10.77 & 22.12 & 32.1 & 27.95 \\
\hline
\end{tabular}


menos em comparação com os prognósticos de 120 minutos, tanto espacialmente quanto temporalmente. Isso pode ser devido ao fato de analisarmos os valores de precipitação em um único pixel de chuva do radar, desconsiderando os valores de pixel ao seu redor.

Para estudar o comportamento da variabilidade da chuva média espacial, na Figura 6 podem ser observadas as séries temporais da precipitação em diagnóstico e prognósticos, específicas para o evento chuvoso com início em 12/04/2014. Analisar os gráficos de séries temporais permite comparar o comportando das previsões nos instantes de maiores intensidades de precipitação. As previsões de 30, 60 e 90 minutos superestimaram os valores em milímetro, no entanto a previsão de 120 subestimou os valores de precipitação. É interessante constatar que existe uma defasagem no início das precipitações mais intensas, se comparados os prognósticos entre si. As previsões de 120 minutos antes do presente, por exemplo, parece apresentar um retardo ao indicar o maior pico de precipitação, o que também pode ser observado nos demais prognósticos de 90, 60 e 30 minutos, porém em menor grau sucessivamente. Isso ocorre, pois o método de cross-correlation mantém as intensidades da última imagem em diagnóstico, sendo necessário que a última imagem esteja mais próxima das intensidades do campo de precipitação observada. Entretanto, o comportando oposto pode ser observado na série temporal no período de decaimento dos acumulados de precipitação. As projeções tendem a manter acumulados de precipitação elevados quando já não é representado o mesmo padrão pelo diagnóstico do radar, ao fato de que para as intensidades sejam menores, é preciso que na imagem do tempo presente essa acentuação esteja explicita.

Figura 6: Média espacial da chuva para o evento de 00:00 12/04/2014 a 23:30 15/04/2014 (radar em diagnóstico -linhas em vermelho, prognósticos -linhas tracejadas, pluviômetro - barras azuis) em 30 minutos (acima a esquerda), 60 minutos (acima a direita), 90 minutos (abaixo a esquerda) e 120 minutos (abaixo a direita) de previsão.

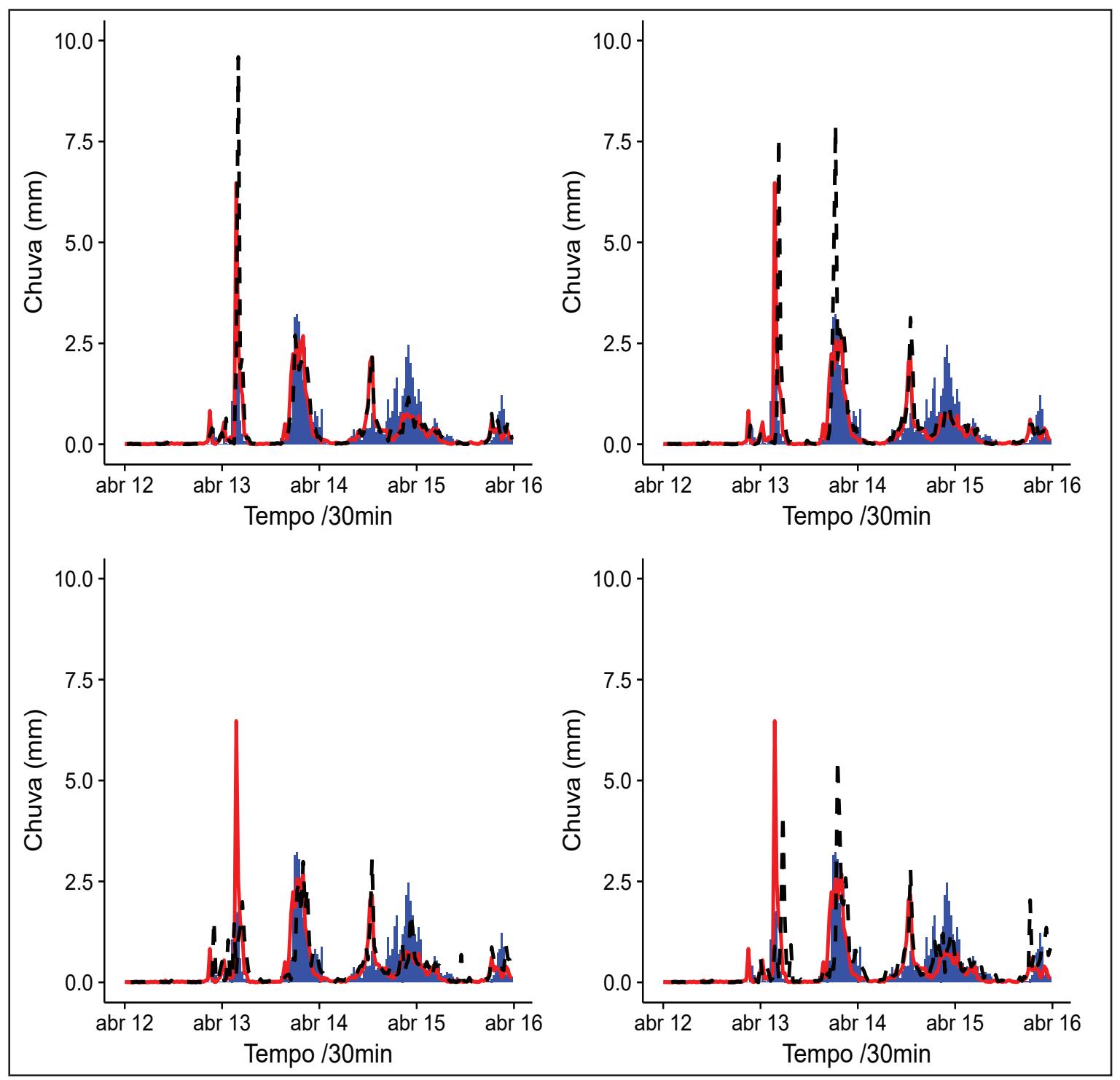


Também é interessante notar que ao comparar as projeções de 120 minutos com as demais, também é perceptível uma tendência à superestimativa quando a distribuição da chuva é mais regular e menos intensa. Apesar dos prognósticos de 120 minutos apresentarem menor PBIAS, as oscilações entre subestimação e superestimação ao longo da série temporal, em adição ao retardo dos picos, confluem para maiores índices de MAE e RMSE. De acordo com o manual do usuário do Rainbow 5 (SELEX, 2012), o cross-correlation é apresentado como um método linear sobreposto a uma estimativa de precipitação Z-R logarítmica, as diferenças mais significativas se mostram principalmente nas chuvas mais fracas entre 0.08 e $0.12 \mathrm{~mm} / \mathrm{hora}$, ou 0.04 e $0.6 \mathrm{~mm} / 30 \mathrm{minutos}$, ou seja, os correlações tendem a diminuir quanto menor for a intensidade das precipitações.

Uma das limitações dos métodos de cross-correlation foi apontada por Dixon et al. (1993). A análise como a demonstrada neste estudo, inclui todas as células convectivas detectadas em volume, mesmo que os núcleos de chuva apresentem um ciclo de vida menor que o intervalo dos acumulados em prognóstico. Por exemplo, uma tempestade com ciclo de vida menor que 15 minutos não será possível de ser percebida em um prognóstico de 30 minutos, uma vez que toda sua evolução se manteve dentro deste intervalo. Isso também pode estar relacionado com a variabilidade temporal que as previsões de 120 minutos demonstrou anteriormente. O pico de acumulado espacial mais intenso foi subestimado na previsão de 120 minutos, provavelmente, pois havia outras áreas de chuva com ciclo de vida menor que 120 minutos que deixaram de ser contabilizadas no início da projeção. Para avaliar melhor o tracking ou acompanhamento do ciclo evolutivo das tempestades, a análise neste estudo deveria incluir somente as áreas de precipitação que pudessem ser previstas em passos de tempo menores que o seu ciclo de vida. Porém como o interesse é mensurar a real previsibilidade dos acumulados de chuva, a Figura 7 expõe os cálculos da tabela de contingência (Dixon et al., 1993) para os limiares de 1, 5, 10, 20 e 30 milímetros de chuva.

Figura 7: Índices de Probabilidade de detecção - POD (a direita), Falsos alarmes - FAR (ao centro) e Sucesso Crítico (CSI) para os prognósticos de 30, 60, 90 e 120 minutos.
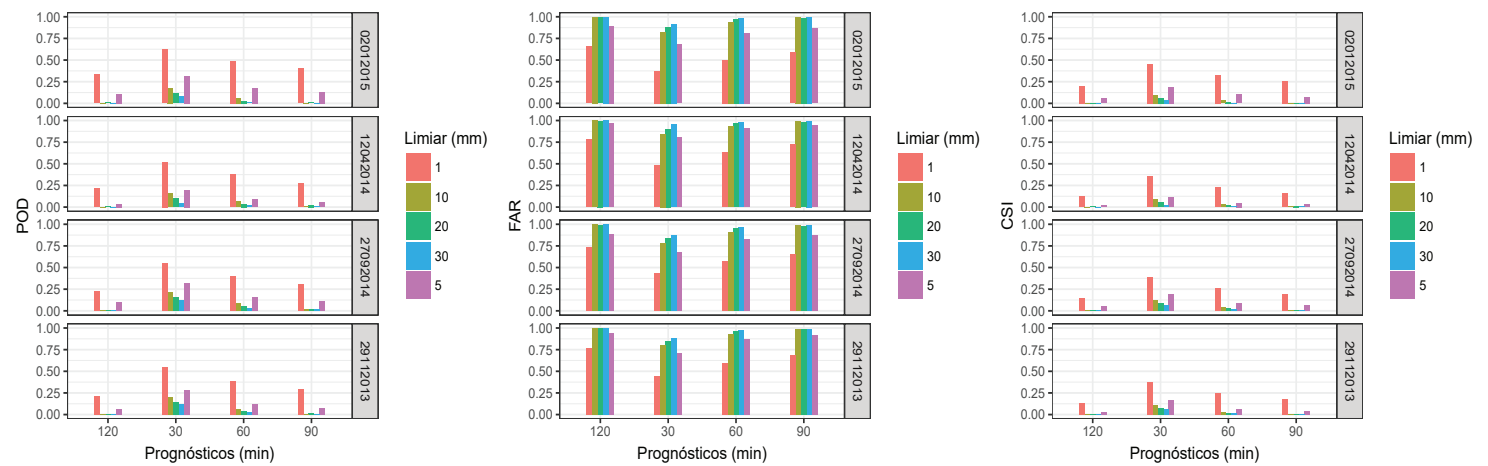

As pontuações de POD na Figura 7 indicam que quanto menor são os limiares de chuva pré-estabelecidos, mais fácil é sua probabilidade de detecção pelos prognósticos. As previsões conseguem representar melhor os valores de limiar com pelo menos 1 mm, em comparação com os limiares de pelo menos 5, 10, 20 ou 30 milímetros, seja qual for seu horizonte temporal de previsão. Porém, a probabilidade dos valores acima de $1 \mathrm{~mm}$ serem detectados diminui conforme os prognósticos se afastam do tempo presente. Os prognósticos de 30 minutos apresentam valores maiores de POD comparados aos de 120 minutos, em qualquer um dos limiares de chuva. A análise de detecção de precipitações acima de $1 \mathrm{~mm}$ permite estabelecer o grau de acerto dos prognósticos na estrutura espacial da chuva, tomando que as chuvas se tornam representativas acima de $1 \mathrm{~mm}$. Este grau de acerto relacionado ao POD diminui enquanto aumenta a complexidade dos prognósticos em acertarem limiares maiores, como pelo menos 5, 10, 20 ou 30 milímetros de chuva. A probabilidade de detecção de precipitações acima de 30 milímetros é a menor em qualquer tempo de prognóstico, seus menores valores são apresentados nos prognósticos de 120 minutos e os maiores valores nos prognósticos de 30 minutos. Em todos os quatro eventos de chuva analisados, 29/11/2013, 12/04/2014, 27/09/2014 e 02/01/2015 existem uma concordância às análises descritas acima. Porém, os melhores índices de POD foram contabilizados durante as comparações do caso de início em 02/01/2015. Em média, os valores de POD considerando todos os limiares de chuva são de 0.24 para 30 minutos, 0.13 para 60 minutos, 0.08 para 90 minutos e 0.06 para 120 minutos de previsão.

Incluso na Figura 7 também estão representados os índices de falsos alertas dos prognósticos de chuva. Os índices de FAR são superiores aos de POD, o que indica que os prognósticos tendem a localizar pixels de chuva com valores superiores aos do diagnóstico, em todos os limiares pré-estabelecidos. Tomando todos os horizontes temporais dos prognósticos para a condição de pelo menos $1 \mathrm{~mm}$ de chuva, a média de FAR se mantém a 0.60, e para pelo menos $30 \mathrm{~mm}$ de chuva 0.96. Dixon et al. (1993) na avaliação de seus prognósticos pelo método TITAN, encontraram valores de FAR entre 0.63 e 0.83 . Contudo, sua metodologia considerou o tempo de vida do tracking das tempestades, bem como se os passos de tempo representavam pelo menos metade do ciclo da precipitação. Nesta análise, os valores altos de FAR para limiares de chuva mais intensa indicam a dificuldade de prever com exatidão os deslocamentos principalmente dos núcleos mais intensos de precipitacão. O inverso do padrão dos índices de 
probabilidade de detecção é observado ao analisar os índices de falso alerta, quanto menon são os limiares de precipitação mais baixos são os valores de FAR. Dentre os casos analisados, a chuva que se iniciou em 27/09/2014 se mostrou com menores valores de FAR, em todos os prognósticos.

Além de considerar o número de pixels com falsos alertas, o índice de CSI também contabiliza o número de falhas nos prognósticos, ou seja, quando as previsões deixaram de apresentar um limiar em comparação às imagens de diagnóstico da chuva do radar. Por isso, o índice de CSI perfaz uma combinação das estatísticas de POD e FAR, e tendem a ser menores do que os valores de POD. O índice revela que o caso com início em 02/01/2015 apresentou maiores valores de CSI nos prognósticos para limiares acima de 1 e 5 milímetros, porém os casos de 12/04/2014 e 27/09/2014 foram encontrados resultados mais significativos para 20 e 30 milímetros de chuva. Isso indica que a previsibilidade de limiares com maiores acumulados de precipitação podem variar principalmente de acordo com o comportamento dos mecanismos de convecção, e sua descrição do evento ao longo do crescimento, maturação e dissipação das nuvens. Hamill e Nehrkorn (1993) mostraram que para imagens de satélite, as projeções em até 2 horas apresentavam um índice de CSI em média de 0.45. Nos casos analisados neste estudo, a média de CSI para os prognósticos de 30 minutos é de 0.15 e para 120 minutos, 0.03 . Considerando apenas os pixels acima de $1 \mathrm{~mm}$ de chuva, os valores de CSI aumentam para 0.39 em 30 minutos de previsão e 0.14 em 120 minutos. Outro fator a ser considerado ao baixo desempenho das estatísticas de POD, FAR e CSI, se deve as imagens não terem sofrido upscale (diminuição da resolução espacial) para sua avaliação, os dados permanecem na resolução espacial original do radar, que é de aproximadamente 1 km. Hamill e Nehrkorn (1993) utilizaram um domínio de 512 x 512, em 5.5 km de resolução espacial, bem como Dixon et al. (1993) utilizaram uma grade de $5 \mathrm{~km}$ do radar meteorológico, em um domínio de $400 \mathrm{~km}^{2}$. A decisão de não modificar as resoluções espaciais, facilita uma aproximação real dos índices obtidos neste trabalho, visando estarem mais correlacionados com os resultados obtidos com técnica em ambiente operacional do Cemaden.

Em trabalhos envolvendo maiores resoluções espaciais e temporais, Ruzanski et al. (2011) encontraram um CSI de aproximadamente 0.5 após 10 minutos de previsão a uma resolução espacial de $0.5 \mathrm{~km}$.Liang et al. (2010) obteve um CSI de aproximadamente 0.35 após 60 minutos para ecos na faixa de 15-45 $d B Z$ à $2 \mathrm{~km}$ de resolução espacial. Berenguer et al. (2005) encontrou um CSI, para previsões de reflexividade de 60 minutos a $1 \mathrm{~km}$ de resolução, de aproximadamente 0.5 para chuvas generalizadas e na faixa de 0.1 a 0.3 para convecção isolada. Poli et al. (2008) descobriram que o CSI era geralmente baixo no início e no final de uma tempestade, atingindo um pico de cerca de 0,4 para uma resolução de $1 \mathrm{~km} \mathrm{em} t+60$ minutos de previsões de refletividade superiores a $30 \mathrm{dBZ}$. Wang (2009) demonstraram que o desempenho geral dos sistemas correntes de nowcasting melhorou nos anos de 2000 à 2008 (trabalho realizado para as olimpíadas de Beijing-2008). Eles mostraram que o CSI máximo para as previsões de acumulação de precipitação por hora superior a $1 \mathrm{~mm} / \mathrm{h}$ aumentou de $0.2 \mathrm{em} 2000$ para 0.45 em 2008, embora o CSI máximo para chuva superior a $10 \mathrm{~mm} / \mathrm{h}$ ainda estivesse em apenas 0.15. Lee et al. (2007) descobriram que o CSI diminuiu com o aumento da taxa de chuva e o tempo de execução previsto: o CSI para previsões de precipitação de 60 minutos diminuiu, em seus estudos, de $0.60 \mathrm{em} 0.1 \mathrm{~mm} / \mathrm{h}$ para 0.2 para taxas de chuva de $10 \mathrm{~mm} / \mathrm{h}$. Ebert et al. (2004) relataram que o CSI para chuva superior a 20 $\mathrm{mm} / \mathrm{h}$, em seus estudos, era quase zero.

\section{Conclusões}

Em suma, os resultados demonstraram que os prognósticos do radar meteorológico Pico do Couto podem ser úteis para aplicações de nowcasting da chuva. Foi observado o mesmo padrão estudado anteriormente, que as previsões por cross-correlation diminuem a confiabilidade conforme se distanciam do tempo presente. Os dados de estimativa de chuva pelo radar meteorológico necessita de melhores correções após a aplicação do método SRI, que neste estudo foi escolhido um fator multiplicador constante, mas que pode existir outras alternativas que gerem melhores resultados. Apesar do método SRI necessitar de correção, as estimativas de chuva derivada se mostraram com menor necessidade de correção se comparados aos dados de CAPPI ou PPI, visto que o fator de correção foi tomado como um menor número. Seguindo em comparação com os dados de pluviômetros, tanto os diagnósticos do radar quanto suas projeções parecem superestimar significantemente a chuva. Este fato pode ser reflexo da falta de calibração das estimativas de chuva. Quanto maior é o horizonte temporal das projeções, menores são seus ajustes com os dados de diagnóstico do radar, estes são mais perceptíveis no início e no final das precipitações. O maior grau de confiabilidade em detectar precipitações intensas é observado no primeiro passo de tempo de 30 minutos, enquanto que à medida que os prognósticos avançam a confiabilidade diminui. $\mathrm{O}$ índice de acerto dos prognósticos também esta relacionado à quantidade de chuva avaliada, as previsões pelo radar tendem a ter baixa confiabilidade em acumulados de chuva de maior grandeza.

\section{Referências}

Bacelar, L., Angelis, C., Costa, I., Rodiguez, M., Damé, R., Teixeira, C. (2013). Limiares de chuva deflagrafores de inundação brusca para bacias da região serrana do rio de janeiro: Radar meteorológico versus pluviômetros. Em: Proceedings..., Simpósio Brasileiro de Recursos Hídricos. 
Berenguer, M., Corral, C., Sanchez-Diezma, R., Sempere-Torres, D. (2005). Hydrological validation of a radar-based nowcasting technique. Journal of Hydrometeorology, 6, 532-549.

Biggerstaff, M. I., Listemaa, S. A. (2000). An improved scheme for convective/stratiform echo classification using radar reflectivity. Journal of Applied Meteorology, 39(12), 2129-2150, URL https:// doi .org/10.1175/1520-0450 (2001) $040<2129$ : AISFCS $>2$.0.CO; 2, https://doi.org/10.1175/1520-0450(2001) 040<2129:AISFCS>2.0. $\mathrm{CO} ; 2$.

Ceped-UFSC (2012). Atlas brasileiro de desastres naturais 1991 a 2010: volume brasil. Relatório Técnico, relatório Técnico.

Dixon, M., Wiener, G. (1993). Thunderstorm identification, tracking, analysis and nowcasting - a radar based methodology. Journal of atmospheric and oceanic technology, 10(6), 785 -797.

Dixon, M., Wiener, G., Dixon, M., Wiener, G. (1993). Titan: Thunderstorm identification, tracking, analysis, and nowcasting - a radar-based methodology. Journal of Atmospheric and Oceanic Technology, 10, 785-797, URL http: / journals . ametsoc.org/doi/abs/10.1175/1520-0426\{\%\}281993\{\%\}29010\{\%\} 3C0785\{\%\} 3ATTITAA \{\%\} 3E2.0. $\mathrm{CO}\{\circ\} 3 \mathrm{~B} 2$.

Ebert, E. E., Wilson, L. J., Brown, B. G., Nurmi, P., Brooks, H. E., Bally, J., Jaeneke, M. (2004). Verification of nowcasts from wwrp sydney 2000 forecast demonstration project. Weather and Forecasting, 19, 73 - 96.

Germann, U., Zawadzki, I. (2004). Scale dependence of the predictability of precipitation from continental radar images. part ii: Probability forecasts. Journal of Applied Meteorology, 43, 74-89.

Hamill, T. M., Nehrkorn, T. (1993). A short-term cloud forecast scheme using cross correlations. CWeather and Forecasting, 8(4), 401-411.

Intrieri, E., Gigli, G., Mugnai, F., Fanti, R., Casagli, N. (2012). Design and implementation of a landslide early warning system. Engineering Geology, 147-148, 124-136.

Lee, G., Seed, A. W., Zawadzki, I. (2007). Modeling the variability of drop size distributions in space and time. Journal of Applied Meteorology and Climatology, 46, 742-756.

Liang, Q., Feng, Y., Deng, W., Hu, S., Huang, Y., Zeng, Q., Chen, Z. (2010). A composite approach of radar echo extrapolation based on trec vectors in combination with model-predicted winds. Advances in Atmospheric Sciences, 27(5), 1119- 1130.

Machado, L. A., Maria, A., Heuminski, G., Felipe, P., Albrecht, R. (2017). PROJETO SOS- CHUVA ( Sistema de Observação e Previsão de Tempo Severo ) Previsão Imediata de Tempestades Intensas e Entendimento dos Processos Físicos no Interior das Nuvens. , pp. 1-48.

Nielsen, J. E., Throndahl, S., Rasmussen, M. R. (2014). A numerical method to generate high temporal resolution precipitation time series by combining weather radar measurements with a nowcast model. Atmospheric Research, pp. 1- 12.

Poli, V., Alberoni, P., Cesari, D. (2008). Intercomparison of two nowcasting methods: preliminary analysis. Meteorology and Atmospheric Physics, 101(doi: 10.1007/s00703-007-0282-3), 229-244.

Rastogi, R. G., Deshpande, M. R., Vadher, M. N., Davies, K., Parikh, P. B. (1978). Three-dimensional storm motion detection by conventional weather radar. Nature, 273.

Ruzanski, E., Chandrasekar, V., Wang, Y. (2011). The casa nowcasting system, journal of atmospheric and oceanic technology. , $28,640-655$.

Seed, A. (2003). A dynamic and spatial scaling approach to advection modeling. Journal of Applied Meteorology, 42,381 - 388.

SELEX (2012). Rainbow 5 sofware manual - products and algorithms. Selex ES GmBH Gematronik Weather Radar Systems, Release 5.46.0, 514.

Steiner, M., Jr., R. A. H., Yuter, S. E. (1995). Climatological characterization of three-dimensional storm structure from operational radar and rain gauge data. Journal of Applied Meteorology, 34(9), 1978-2007, URL https://doi.org/10.1175/1520-0450 (1995) 034<1978: CCOTDS>2.0.CO;2, https://doi.org/ $10.1175 / 1520-0450(1995) 034<1978: \operatorname{COTDS}>2.0 . \mathrm{CO} ; 2$. 
Thorndahl, S., Rasmussen, M. R. (2013). Short-term forecasting of urban storm water runoff in real-time using extrapolated radar rainfall data. Journal of Hydroinformatics, 15(3), 897, URL http: / / www. i waponline.com/jh/015/ jh 0150897. htm.

Thorndahl, S., Poulsen, T. S., Thomas, Borup, M., Ahm, M., Nielsen, J. E., Grum, M., Rasmussen, M. R., Gill, R., Mikkelsen, P. S. (2013). Comparison of short-term rainfall forecasts for modelbased flow prediction in urban drainage systems. Water Science and Technology, 68(2), 472-478.

Tominaga, L., Santoro, J., Amaral, R. (2009). Desastres naturais. : conhecer para prevenir. São Paulo : Instituto Geológico, URL http://www.igeologico.sp.gov.br/downloads/livros/DesastresNaturais.pdf.

UCAR (2010). Flash flood early warning system reference guide. URL http: / / www . meted. ucar.edu/communities / hazwarnsys/ffewsrg/FF\{_\}EWS.pdf.

Vicente, G. A., Scofield, R. A., Menzel, W. P. (1998). The operational goes infrared rainfall estimation technique. Bull Amer Meteor Soc, 79, 1883-1898.

Vila, D. A., de Goncalves, L. G. G., Toll, D. L., Rozante, J. R. (2009). Statistical Evaluation of Combined Daily Gauge Observations and Rainfall Satellite Estimates over Continental South America. Journal of Hydrometeorology, 10(2), 533-543.

Wang, J. (2009). Overview of the beijing 2008 olympics project. part i. Forecast Demonstration Project, A report to the WMO World Weather Research Programme.

\section{Luiz Carlos Salgueiro Donato Bacelar}

Instituto Nacional de Pesquisas Espaciais, Brasil E-mail: luiz.bacelar@cemaden.gov.br

Participação do autor:

redigiu o trabalho, fez análise e interpretação de dados;

\section{Carlos Frederico de Angelis}

Instituto Nacional de Pesquisas Espaciais, Brasil

Participação do autor:

Orientou o trabalho e realizou uma revisão substancial 